\title{
Imaginarios sociales y representaciones: su aplicación a análisis discursivos en tres ámbitos diferentes ${ }^{l}$
}

\section{Social imaginaries and representations: their application to discursive analysis in three different areas}

\section{Pablo Segovia Lacoste}

Universidad de Concepción-Chile

psegovialacoste@gmail.com

\section{Oscar Basulto Gallegos}

Universidad Católica de la Santísima Concepción-Chile obasulto@ucsc.cl (CHILE)

\section{Pablo Zambrano Uribe \\ Universidad Concepción-Chile pabzambrano@udec.cl}

Recibido: 04.06.2018

Aceptado: 24.08.2018

\section{RESUMEN}

Este artículo analiza las nociones de representaciones e imaginarios sociales a través del estudio de textos periodísticos en tres estudios de casos pertenecientes a tres ámbitos del acontecer nacional en Chile: el movimiento estudiantil de 2011, la asociación droga-delito y el conflicto chileno-mapuche. El objetivo principal es reflexionar sobre las nociones de representaciones e imaginarios sociales y diferenciarlas en los textos analizados con el objetivo de identificar los aportes de estas nociones en la construcción de una realidad social, en sentido de Berger y Luckmann (1976). Se propone como tesis que las nociones de representaciones e imaginarios sociales nos remiten a niveles de análisis diferenciados en

${ }^{1}$ Este trabajo fue posible gracias al apoyo de los proyectos PAI/CONICYT n ${ }^{\circ} 82140053$ del Dr. Pablo Segovia y Postdoctorado FONDECYT n 3170473 del Dr. Óscar Basulto. 
lo que concierne a la construcción e interpretación de la realidad social. Las representaciones conducen a un plano de lo aparente, en tanto que los imaginarios sociales constituyen el plano fundante de significación de la sociedad.

La metodología empleada es de carácter cualitativa y se aplica el Análisis de Contenido para el estudio de caso que concierne el movimiento estudiantil de 2011, el Análisis Sociológico del Discurso para el estudio de caso que aborda la asociación droga-delito y el Análisis del Discurso para estudiar la mediatización del conflicto chileno mapuche. Los resultados del trabajo resaltan la importancia de la aplicación de las nociones de representaciones e imaginarios sociales al estudio de la prensa escrita Asimismo, este trabajo profundiza en la distinción entre imaginarios y representaciones con el objetivo de proponer pistas de investigación para el estudio de textos periodísticos.

\section{PALABRAS CLAVE} ción.

Representaciones, imaginarios sociales, discurso periodístico, criminaliza-

\section{ABSTRACT}

This article analyzes the notions of social representations and imaginaries through the study of journalistic texts in three case studies belonging to three areas of national events in Chile: the student movement of 2011, the drug-crime association and the Chilean-Mapuche conflict. The main objective is to reflect on the notions of social representations and imaginaries and differentiate them in the analyzed texts with the objective of identifying the contributions of these notions in the construction of a social reality, in the sense of Berger and Luckmann (1976). It is proposed as a thesis that the notions of social representations and imaginaries refer us to levels of differentiated analysis regarding the construction and interpretation of social reality. The representations lead to a plane of the apparent, while the social imaginaries constitute the foundational plane of meaning of society. The methodology used is of a qualitative nature and the Content Analysis is applied to the case study that concerns the student movement of 2011, the Sociological Analysis of the Discourse for the case study that deals with the drug-crime association and the Discourse Analysis for study the mediatization of the Mapuche Chilean conflict. The results of the work highlight the importance of application of the notions of representations and social imaginaries to the study of the written press in what concerns the study of social reality. Likewise, this work deepens in the distinction between imaginaries and representations with the objective of proposing research clues for the study of journalistic texts. 


\section{KEY WORDS}

Representations, social imaginaries, journalistic discourse, criminalization.

\section{INTRODUCCIÓN}

Los estudios sobre las nociones de representaciones e imaginarios sociales han tenido un desarrollo notable este último tiempo, lo cual se puede apreciar en diversas revistas científicas y eventos académicos que tienen como eje central alguna o ambas de estas temáticas. Este desarrollo se observa no sólo en el mundo académico, sino también en el ámbito social como se puede evidenciar en diversas normativas jurídicas ${ }^{2}$, enfoques curriculares, así como en el ámbito de los medios de comunicación. Esto ha permitido otorgar un valor práctico y operativo a estas nociones, lo que ha significado la apertura a nuevos campos de investigación para su exploración.

Sin embargo, escasos han sido los esfuerzos por diferenciar estas nociones en ámbitos de aplicación específicos como la Sociología, la Psicología, la Educación, la Salud y las Ciencias de la Comunicación, entre otros. Los trabajos que existen se remiten más al ámbito teórico que al trabajo empírico, aun cuando en el último decenio se han publicado diversos trabajos de aplicación de estas teorías ${ }^{3}$.

En este sentido, nuestro trabajo persigue como objetivo principal reflexionar sobre las nociones de representaciones e imaginarios sociales y diferenciarlas en un ámbito específico, como es el caso de la prensa escrita, para identificar los aportes de estas nociones en la construcción de una realidad social, en sentido de Berger y Luckmann (1976).

La tesis central de nuestro artículo propone que las nociones de representaciones e imaginarios sociales nos remiten a niveles de análisis diferenciados en lo que concierne a la construcción e interpretación de la realidad social. Las representaciones conducen a un plano de lo aparente, mientras que los imaginarios sociales constituyen el plano fundante de significación de la sociedad.

La metodología empleada es de carácter cualitativo-interpretativo y se utilizarán diferentes enfoques (Análisis de Contenido, el Análisis Sociológico del Discurso y el Análisis del Discurso), para el análisis de textos en tres estudios de casos pertenecientes a tres ámbitos del acontecer nacional en Chile de la última década: el movimiento estudiantil de 2011, la asociación droga-delito y el conflicto chileno-mapuche.

\footnotetext{
${ }^{2}$ Véase el trabajo de Coloma y Agüero (2014).

${ }^{3}$ Llama la atención en Chile el incremento de los trabajos en representaciones e imaginarios en los ámbitos de la Educación, la Sociología y la Comunicología. Véase, por ejemplo, Figueroa et al., (2017) y Barrera (2017), Zambrano (2017), Dittus, Basulto y Riffo (2017) respectivamente $\mathrm{y}$ entre otros.
} 


\section{MARCO CONCEPTUAL}

\subsection{Acerca de las nociones de representaciones e imaginarios sociales}

Las representaciones e imaginarios sociales provienen de universos epistemológicos diferentes, lo que incide significativamente en la forma de definir y trabajar con estas nociones.

La noción de representación social aquí planteada tiene su origen en las reflexiones de Serge Moscovici desde la Psicología social. En su libro titulado El psicoanálisis, su imagen y su público, Moscovici (1961) define las representaciones sociales como "sistemas cognitivos con una lógica y lenguaje propios [...] No representan simples opiniones, imágenes o actitudes en relación a algún objeto, sino teorías y áreas de conocimiento para el descubrimiento y organización de la realidad [...]. De acuerdo con este autor (1961), las representaciones sociales poseen la función de establecer un orden con el fin de guiar a los sujetos en el mundo social y permitir la comunicación entre ellos a partir de una serie de elementos en común culturalmente aceptados por una comunidad. Resaltemos dos elementos de esta definición: las representaciones sociales no son simples imágenes, sino que poseen capacidad de significación y la posibilidad de comunicación que ofrecen las representaciones sociales, lo que pone de relieve el rol del lenguaje.

Otro autor que desarrolló la noción de representación social fue Denise Jodelet, para quien las representaciones sociales "se presentan bajo formas variadas, más o menos complejas. Imágenes que condensan un conjunto de significados; sistemas de referencia que nos permiten interpretar lo que nos sucede, e incluso, dar un sentido a lo inesperado; categorías que sirven para clasificar las circunstancias, los fenómenos y a los individuos con quienes tenemos algo que ver; teorías que permiten establecer hechos sobre ellos. Y a menudo, cuando se les comprende dentro de la realidad concreta de nuestra vida social, las representaciones sociales son todo ello junto" (1984:472). Como se puede evidenciar, esta definición enfatiza las múltiples posibilidades que poseen las representaciones para manifestarse en el mundo social, lo que revela su naturaleza multiforme y simbólica, que ofrece muchas veces ciertas dificultad para aprehender esta noción. Una de las maneras de trabajar con las representaciones sociales es por medio de su manifestación en las prácticas discursivas. Volveremos sobre esto más adelante cuando se detallen los procedimientos metodológicos y los análisis.

En relación con la noción de imaginarios sociales aquí tratada, esta tiene su origen en las reflexiones del filósofo Cornelius Castoriadis (1989) aparecidas en la obra La institución imaginaria de la sociedad. Para el autor, existe en cada sociedad un conjunto de significaciones imaginarias que otorgan sentido a la vida en comunidad. Estas significaciones imaginarias no son "ni representaciones, ni figuras, ni formas, ni conceptos" (1989: 523), sino que corresponden a "creaciones libres", "ex nihilo", que no son "deducibles racionalmente". Estas significaciones imaginarias son creadas en y por la sociedad, y se encarnan en las instituciones (lengua, estructuras familiares, normas, leyes) que las portan, lo 
que incita a estudiar la sociedad como un lugar privilegiado de creación imaginaria permanente con capacidad de significación.

A partir de las reflexiones de Castoriadis (1989), el sociólogo Manuel Baeza (2003) definió a los imaginarios sociales como "múltiples y variadas construcciones mentales (ideaciones) socialmente compartidas de significancia práctica del mundo, en sentido amplio, destinadas al otorgamiento de sentido existencial". Para este autor, los imaginarios sociales surgen como una creación incesante de respuestas frente a los diferentes enigmas que plantea la vida en sociedad. En medida que las respuestas se hace colectivas, los imaginarios sociales funcionan como "homologadores de todas las maneras de pensar, de todas las modalidades relacionales", una suerte de matriz común. Sin embargo, esta matriz no está exenta de contradicciones y contradiscursos, lo que revela una lucha incesante por conquistar el espacio público, donde coexisten diferentes imaginarios. Para dar cuenta de estas contradicciones, Baeza $(2003,2007)$ propone los términos de "imaginarios sociales dominantes" e "imaginarios sociales dominados". El primer término corresponde a los imaginarios que han triunfado de manera provisoria en el terreno simbólico. El segundo término corresponde a los imaginarios que han perdido provisoriamente la lucha simbólica en el terreno de los social. De este modo, los imaginarios sociales se encuentran en constante tensión y emergen a través de las prácticas discursivas en diferentes momentos de la vida cotidiana.

\subsection{Distinción entre representaciones e imaginarios sociales}

Para los autores Donot y Pordeus (2012), existen dos elementos importantes concernientes al empleo de las nociones imaginarios y representaciones. Por un lado, la banalización de estas, que suelen ser empleadas como sinónimos sin reparar en la distinción entre ellas. Este fenómeno es recurrente y pone en duda la rigurosidad propia del trabajo científico. Por otro lado, el encierro disciplinar o el comportamiento estanco en el cual se enmarcan estas dos nociones. Por ejemplo, casos paradigmáticos son el de la Psicología Social y la Educación que toman partido por la noción de representaciones. Por el contrario, la Sociología opta preferentemente por la noción de imaginarios sociales. Las causas de dichas elecciones reposan sobre varios factores, entre ellos, la tradición disciplinar que ejerce una fuerte influencia al momento de trabajar con una u otra noción. Otra causa reside en el peso epistemológico que poseen autores emblemáticos, tal como Moscovici en Psicología Social, Jodelet en Educación, Durand en Antropología y Castoriadis en Sociología. Esto último revela una reflexión más ligada a la figura del autor en lugar de enfocarse sobre el problema de investigación y su objeto de estudio. En este sentido, Baeza (2003) señala que para trabajar con las nociones de representaciones e imaginarios es necesario ir más allá de las fronteras disciplinares con el objetivo de establecer conexiones con otras disciplinas, lo que revela un esfuerzo interdisciplinar por parte del investigador. 
Otra problemática recurrente en torno al empleo de las nociones de imaginarios sociales y representaciones dice relación con los niveles de análisis, puesto que nos parece, siguiendo a Baeza (2008), que las representaciones se encuentran en un plano de significación más aparente, mientras que los imaginarios sociales nos remiten a un plano de significación fundante y constitutivo de la sociedad. En otras palabras, las representaciones nos remiten a imágenes culturales que funcionan como marcos interpretativos de la sociedad, mientras que los imaginarios serían, en la lógica de Baeza (2008), la base sobre la cual se construye e instituye permanentemente la sociedad, dado que serían los propios imaginarios los que posibilitarían la existencia de representaciones, luego de haberse "instituido" el mundo, en el sentido de Castoriadis (1989).

Siguiendo con la distinción entre imaginarios sociales y representaciones, otra idea fundamental dice relación con la referencia a una realidad externa en lo tendiente a las representaciones. En esta línea, de acuerdo con Jodelet (1984), la representación correspondería a algo o a alguien (la sociedad misma), o aquello que "está afuera" en el lenguaje de Seveso (2009), mientras que los imaginarios sociales serían creación incesante de figuras, formas e imágenes que construyen y desbordan el propio orden social, y no una imagen o reflejo aparente de la sociedad como lo plantearían las representaciones.

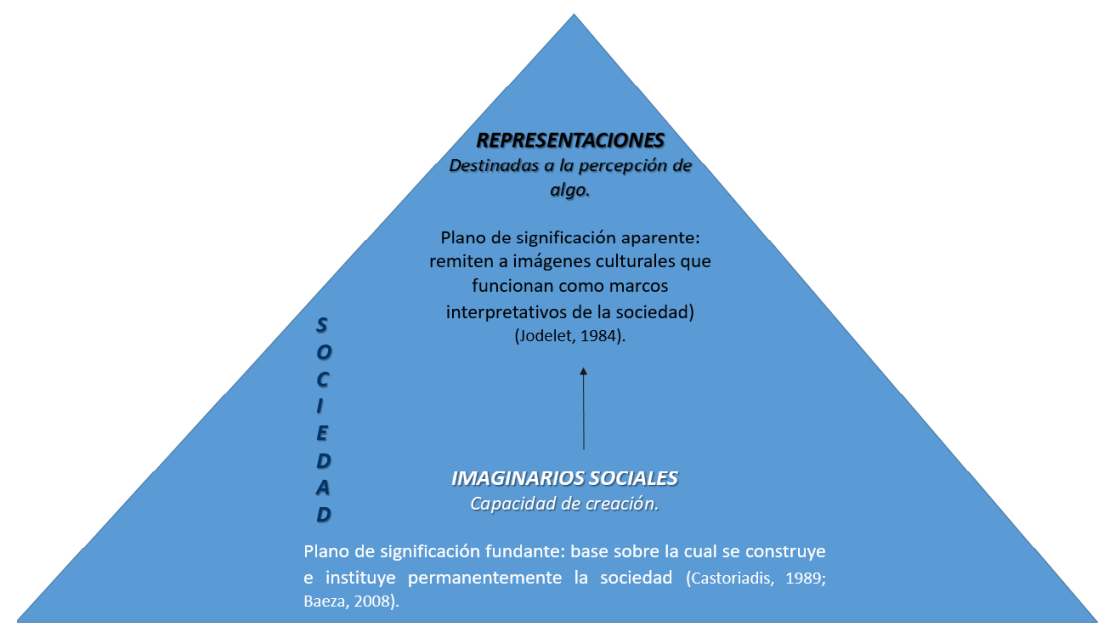

Esquema 1: "Plano de significación representacional e imaginario". Elaborado por Oscar Basulto (2018)4.

En el esquema se hace alusión a dos planos de significación social complementarios. En la base de la pirámide se encuentran los imaginarios sociales, que constituyen los cimientos de la construcción del entendimiento intersubjetivo de

${ }^{4}$ Esquema elaborado en el marco del presente artículo y del Proyecto de Postdoctorado $\mathrm{N}^{\circ}$ $3170473(2017-2019)$

EMPIRIA. Revista de Metodología de Ciencias Sociales. N. 41 septiembre-diciembre, 2018, pp. 79-102. ISSN: 1139-5737, DOI/empiria.41.2018.22605 
los individuos que interactúan en una sociedad. Aquí surgen los imaginarios sociales que se resignifican permanentemente a lo largo de la historia y se materializan en las instituciones y en las leyes. En este sentido, Castoriadis (1989:494) nos señala “(...) el magma de las significaciones imaginarias sociales cobran cuerpo en la institución de la sociedad considerada y que, por así decirlo, la animan. Semejantes significaciones sociales imaginarias son, por ejemplo, espíritus, dioses, Dios, polis, ciudadano, nación, Estado, partido, mercancía, dinero, capital (...), tabú (...), pecado, etc (...)”. Por su parte, en la cúspide de la pirámide se ubican las representaciones sociales, que se encuentran en un plano de significación social más superficial. Siguiendo a Jodelet (1984), las representaciones son imágenes culturales emanadas de la interacción cultural en sociedad. Bajo esta lógica, las representaciones podrían ser tanto la punta del iceberg de algo que no podemos ver sin un ejercicio reflexivo-hermenéutico profundo de las bases de la sociedad (alude a un imaginario), como también la percepción aparente subjetiva y/o intersubjetiva frente a algo que interviene la realidad social. Es decir, una construcción a partir de la imagen y no desde lo imaginario. En consecuencia, se puede observar una complementariedad operativa de las nociones de representaciones e imaginarios. La articulación entre estas dos nociones se realiza debido a la naturaleza simbólica y explicativa que comparten. Ambas nociones pueden intervenir hermenéuticamente en la interpretación (Gadamer 2000) y construcción de la realidad social (Berger y Luckmann 1976).

\section{METODOLOGÍA Y JUSTIFICACIÓN DEL MATERIAL DE ANÁLISIS}

La metodología empleada para el desarrollo de este trabajo es de carácter cualitativa-interpretativa (Gadamer 2000). El objetivo principal que se propone es reflexionar sobre las nociones de representaciones e imaginarios sociales a través del análisis de cinco noticias de la prensa escrita chilena para identificar los aportes de estas nociones en la construcción de realidad social. Los objetivos específicos son identificar y diferenciar ambas nociones a través del análisis de cinco textos periodísticos pertenecientes a tres ámbitos del acontecer nacional en Chile: movimiento estudiantil de 2011, asociación droga-delito y conflicto chileno-mapuche.

Para llevar a cabo la investigación, se ha escogido trabajar con fuentes secundarias, específicamente con el discurso periodístico chileno a través del análisis de cinco noticias extraídas de los diarios El Mercurio ${ }^{5}$ y La Tercera ${ }^{6}$. La

${ }^{5}$ La Sociedad Anónima Periodística El Mercurio es una empresa de medios de comunicación chilena, perteneciente a la familia Edwards y junto al grupo COPESA concentra gran parte de los medios de comunicación del país, motivo por el cual se refiere a nivel nacional en términos de un duopolio mediático.

${ }^{6}$ El diario La Tercera pertenece al grupo empresarial COPESA, que como ya mencionamos es uno de los dos grandes grupos que controla gran parte de la prensa en Chile. Desde esta pers- 
razón principal de esta elección se debe a que las noticias, y la prensa en general, es un lugar privilegiado donde se ejerce y se reproduce el discurso hegemónico (Van Dijk, 2007), lo que permite evidenciar posiciones dominantes y dominadas sobre un tema de interés nacional que se expresan mediante el lenguaje escrito. De esta manera, al interior de un conflicto social mediatizado por los diarios El Mercurio y La Tercera, tales como el conflicto estudiantil de 2011, la asociación droga-delito y el conflicto chileno-mapuche, se puede apreciar un conjunto de representaciones e imaginarios sociales que reflejan una lucha simbólica por conquistar el espacio público. Esto permite reflexionar sobre la distinción entre imaginarios y representaciones sociales, y de qué manera estas nociones participan en la construcción de una realidad social, en el sentido de Berger y Luckmann (1976), promovida por la prensa escrita.

En relación con el análisis del texto periodístico que aborda el movimiento estudiantil de 2011, se utilizará como procedimiento metodológico el Análisis de Contenido, que será complementado con los enfoques hermenéutico (Gadamer 2000; Martyniuk 1994), sociosemiótico (Verón 1993), fenomenológico (Husserl 1985; Schütz 1993; Baeza 2003) y constructivista sistémico (Pintos 1995; Arnold 2003). Por Análisis de Contenido se entenderá "el conjunto de técnicas de análisis de las comunicaciones tendientes a obtener indicadores (cuantitativos o no) por procedimientos sistemáticos y objetivos de descripción del contenido de los mensajes permitiendo la inferencia de conocimientos relativos a las condiciones de producción/recepción (contexto social) de estos mensajes" (Bardin 1996: 32). Resaltemos dos elementos fundamentales de esta metodología que se utilizará en el análisis de dos textos periodísticos del diario El Mercurio: la descripción del contenido semántico y las inferencias interpretativas a partir de las condiciones de producción del texto. Esto último posee gran relevancia, debido a que las inferencias que se extraen de los textos poseen un soporte textual y buscan reconstituir las condiciones de producción del texto, fenómeno que ha sido estudiado anteriormente por Verón (1993) y Gadamer (2000).

Cabe señalar que los análisis del tratamiento mediático del movimiento estudiantil de 2011 forman parte del proyecto de Postdoctorado denominado "Imaginarios de la criminalización y la descriminalización del movimiento estudiantil chileno: acciones/reacciones sociales y distorsión mediática en las ciudades de Santiago y Concepción", dirigido por el investigador Óscar Basulto y financiado por el Fondo Nacional de Desarrollo Científico y Tecnológico (FONDECYT), Chile.

En lo que respecta al análisis de una noticia que aborda la asociación drogadelito, se utilizará como procedimiento metodológico el Análisis Sociológico del Discurso (ASD), propuesto por el sociólogo Ruiz (2009). La propuesta de este autor se articula en torno a tres niveles diferenciados de análisis: un nivel textual, un nivel contextual y un nivel interpretativo. El nivel textual, en la lógica de

pectiva, La Tercera y El Mercurio se constituyen como dispositivos de poder que revisten gran importancia en el país, en términos de agenda para construir realidad y de generación de opinión pública en un sentido hegemónico. 
Ruiz (2009), nos ofrece una caracterización del discurso, otorgando centralidad al plano del enunciado y considerando el discurso en su dimensión de objeto de estudio. En relación con el nivel contextual, se considera el discurso en su entorno social, otorgándole una gran relevancia al plano de la enunciación al interior del cual un discurso interactúa con otros. Finalmente, el nivel interpretativo proporciona una explicación del discurso, centrándose en el plano sociológico. En este nivel, se considera el discurso en su dimensión informativa, ideológica y como resultado de un producto social.

Cabe señalar que los análisis del tratamiento mediático de la asociación droga-delito forman parte de la tesis de licenciatura titulada "De biopoder y discursos en la construcción imaginario social: En Población condenada a penas sustitutivas derivada a tratamiento de drogas y/o alcohol en la Provincia de Concepción", realizada por el investigador Pablo Zambrano en la Universidad de Concepción, Chile.

En lo que concierne al conflicto chileno-mapuche, se utilizará como procedimiento metodológico el Análisis del Discurso de origen francés. Este campo de trabajo que se encuentra en el cruce entre distintas disciplinas de las Ciencias Sociales (Lingüística, Ciencias de la Información, Historia, Ciencias Políticas, etc.) y su forma de proceder consiste, de manera general, en remitir los discursos a los lugares sociales/institucionales donde se produjeron (Maingueneau 2014). Una definición de discurso en esta perspectiva contempla "la articulación de una co-producción textual a una situación de comunicación y a un género discursivo" (Moirand 2007).

Una problemática nuclear para quienes trabajan en este ámbito consiste en estudiar los géneros discursivos al interior del cual se desarrollan las prácticas discursivas. Por género discursivo, se entenderá, siguiendo a Maingueneau (2014), como un "dispositivo de comunicación determinado sociohistóricamente", que articula en su seno prácticas discursivas y sociales de una determinada comunidad lingüística. En este sentido, todo texto/discurso nos remite necesariamente a un género discursivo.

Para llevar a cabo el análisis de los textos periodísticos, se procederá, en primera instancia, a caracterizar el género discursivo del texto/discurso estudiado. En segunda instancia, se trabajará con aquello que Pêcheux (1969) llamaba "la materialidad discursiva", es decir, los datos textuales que se puede identificar y observar (palabras, sintagmas nominales, nominalizaciones, expresiones idiomáticas y verbos). Se pondrá énfasis en las unidades léxicas y su relación con el contexto, debido a que nos permitirá estudiar los conceptos asociados a determinadas palabras (el contenido proposicional) a lo largo del texto. Este privilegio por las palabras, y su relación con el contexto, se inspira en teoría bajtiniana que concibe las palabras como "portadoras de memoria" y que se encuentran "habitadas" por otros discursos. En tercera instancia, se estudiarán los universos sociales y éticos movilizados por determinadas construcciones discursivas con el fin de crear una interpretación que tenga en cuenta los aspectos lingüísticos y sociales. Es aquí donde intervienen las nociones de representaciones e imagina- 
rios sociales para dar profundidad y valor explicativo a los análisis derivados de los textos.

Cabe señalar que los análisis del tratamiento del conflicto chileno-mapuche en la prensa chilena forman parte del proyecto titulado "La mediatización del llamado conflicto mapuche desde un punto de vista discursivo", dirigido por el investigador Pablo Segovia Lacoste y financiado por el programa PAI/CONICYT “Apoyo al retorno de los investigadores desde el extranjero".

\section{ANÁLISIS DE TEXTOS}

\subsection{La mediatización del movimiento estudiantil de 2011 en el diario El Mercurio}

En este apartado, se analizarán dos noticias del diario El Mercurio que abordan el movimiento estudiantil de 2011 en Chile.

Durante protesta en Av. Salvador:

\section{Encapuchados queman farmacia en Providencia}

Además, apedrearon un banco, una clínica y otro local farmacéutico.

Cerca de las siete de la tarde de ayer, unos veinte encapuchados instalaron barricadas en la esquina de Av. Salvador con calle Alessandri, en Providencia. Según testigos, habrían estado gritando consignas y protestando, cuando comenzaron a quemar objetos y a lanzar contra una farmacia Ahumada [ ...], que se encontraba cerrada.

Tras recibir una bomba molotov, el local se incendió completamente y vecinos llamaron a bomberos. Al momento que llegó la policía, según informó el teniente coronel Héctor González, los encapuchados ya habían huido. "Estos además provocaron daños en la farmacia Salcobrand y en un Banco Estado más al sur, por Avenida Salvador, detalló.

El banco, la farmacia y una clínica ubicada al frente del local incendiado fueron apedreados.

[...] Cerca del lugar hay dos universidades en toma: La Academia de Humanismo Cristiana [...] y la UTEM [...]. Testigos afirmaron que entre los manifestantes podría haber estudiantes que participan de las tomas en esas casas de estudio.

Mientras tres compañías de bomberos trabajaban en la farmacia siniestrada, el químico farmacéutico, quien cerró el local a las 17.30, retiraba los medicamentos "duros" o psicotrópicos del local para dar cuenta al Instituto de Salud Pública (ISP) y así evitar que pudieran ser robados.

Al lugar también llegó contingente de Fuerzas Especiales de Carabineros, que acordonó la cuadra (El Mercurio, 3-07-2011).

Como se observa, el contenido discursivo del texto se refiere a la violencia y destrucción perpetrada por encapuchados que se manifestaron en las calles de Santiago. El procedimiento que utiliza el periodista consiste en reportar los 
acontecimientos para lo cual moviliza las diferentes fuentes de información (vecinos, policías y testigos) que son expuestas bajo el procedimiento de discurso referido (estilo directo e indirecto). La metodología del Análisis de Contenido permite trabajar los aspectos semánticos de los textos, lo que permite acceder a un análisis sobre las representaciones e imaginarios sociales del movimiento estudiantil de 2011.

Un análisis en términos de representaciones enfatiza la imagen del encapuchado, que aparece como sujeto del titular de la noticia, y de las consignas que aluden a las motivaciones ideológicas de estos. Junto a ello, se pone de relieve el accionar de los encapuchados, a través de los verbos empleados (quemar, apedrear, etc), así como también el uso de bombas molotov, lo que orienta la comprensión de la noticia hacia conductas delictivas asociadas con el terrorismo. Otra imagen en la línea de las representaciones corresponde al rol de la policía, que se presenta aquí como garante del Estado, otorgando seguridad a los vecinos y a la empresa privada (en este caso la cadena de farmacias Ahumada).

En lo que se refiere a un análisis en el plano de los imaginarios sociales, se puede señalar que el discurso central de la noticia se articula en defensa de un imaginario social dominante, en el sentido de Baeza (2003, 2007), que corresponde a la legitimación del sistema económico neoliberal y la defensa de la propiedad privada como un valor social fundamental. El imaginario dominado, que corresponde a las demandas del movimiento estudiantil, se presenta invisibilizado, debido a que no se menciona en el texto periodístico ni tampoco el origen del descontento de los estudiantes movilizados.

Otro imaginario social dominante (Baeza 2003, 2007) en la noticia corresponde al de la violencia pública, que nos remite al imaginario de inseguridad urbana (individual/colectiva) que legitima una actuación policial mediante la represión. Aquí surge la figura del encapuchado, que asocia al estudiante con el delincuente, respondiendo de este modo al imaginario del "joven como problema" (Aliaga, Basulto y Apolo, 2014) tan divulgado por la prensa escrita chilena. Además, cabe señalar las alusiones a las demandas del movimiento estudiantil de 2011, las cuales por la prensa hegemónica fueron categorizadas bajo el imaginario de violencia pública, aun cuando dichas demandas formaron parte de la agenda por más de seis meses en Chile y pusieron en jaque al gobierno de derecha de Sebastián Piñera ${ }^{7}$. Si bien hubo algunas menciones en la prensa escrita sobre la creatividad desarrollada por este movimiento estudiantil, esta se vio opacada por los actos de violencia, tal como se puede apreciar en el siguiente ejemplo:

\footnotetext{
${ }^{7}$ Véase el artículo de Arrué (2012).
} 


\section{Minuto a minuto: Masiva marcha estudiantil concluye con detenidos e incidentes aislados (Finalizado)}

La manifestación, que estuvo marcada por la creatividad de los estudiantes, logró convocar a más de 50 mil personas. Durante la jornada hubo trece detenidos por portar bombas molotov (EMOL, 30-06-2011).

Revisemos a continuación otra noticia del diario El Mercurio.

\section{Marcha de ayer reunió a 7 mil personas.}

Una jornada marcada por las protestas se vivió ayer en la Capital. A las 9 de la mañana, tres estudiantes de la $U$. de Chile treparon a una señalética vial ubicada en la Alameda. Carabineros tuvo que interrumpir el tránsito para instalar un operativo de rescate que duró casi una hora. Al mediodía estudiantes, profesores y trabajadores [...] se unieron para marchar. La movilización que no estaba autorizada por la Intendencia reunió a más de 7 mil personas que marcharon [...]. Mientras estudiantes clamaban por el fin del lucro en la educación [...] los trabajadores de Codelco demandaban una renacionalización del Cobre y mejores condiciones de trabajo. El recorrido se realizó con total normalidad, pero al final de la manifestación una minoría provocó una serie de incidentes en el parque Almagro. Todo comenzó cuando un caballo de carabineros embistió a una estudiante, por lo que los manifestantes comenzaron a agredir a los efectivos de fuerzas especiales. En medio de esta escaramuza, algunos participantes hirieron con botellas a los caballos. La movilización finalizó con 38 detenidos y 11 carabineros heridos. El Ministro del Interior, Rodrigo Hinzpeter anunció que se va a aplicar todo el rigor de la ley para quienes vulneraron el orden público. "No corresponde que un grupo de estudiantes que quiera parar, crea que puede arruinarle la vida a los que quieren estudiar, que son muchos más, sentenció (El Mercurio, 16/06/2011).

La noticia se refiere a una manifestación masiva del movimiento estudiantil que finalizó con incidentes en las calles de Santiago. El procedimiento que utiliza el redactor de la noticia consiste, al igual que el texto anterior, en reportar los diferentes acontecimientos a través de la utilización de diversas fuentes. Un análisis a nivel representacional pone énfasis en las imágenes del estudiante rebelde y violento que no respeta el Estado de derecho. De este modo, las secuencias de los estudiantes que trepan sobre una señalética, aquellos que marcha y claman consignas, y algunos que agreden a la policía (Carabineros) refuerzan la representación negativa de este sector de la sociedad. Asimismo, la representación de la policía como resguardadora del orden, que se encarga de la seguridad de todos los miembros de la sociedad (incluso de los estudiantes trepadores), participa de la construcción positiva de este sector de la sociedad. Nótese que incluso se exime de responsabilidad a la policía en los actos de violencia, tal como se menciona en la noticia, donde sería el caballo el responsable de comenzar el conflicto y no el efectivo policial que lo comandaba desde su silla de montar.

${ }^{8}$ EMOl corresponde a la versión digital del diario El Mercurio. 
En lo que concierne a un análisis a nivel de imaginario, se refuerza la idea de un imaginario social dominante (Baeza 2003, 2007) que legitima el modelo neoliberal y resguarda el orden público. En este contexto, las movilizaciones estudiantiles constituyen un imaginario dominado que amenaza la integridad de la sociedad chilena. De esta manera, la representación que realiza el diario El Mercurio del estudiante rebelde y violento participa en la criminalización ${ }^{9}$ de las demandas estudiantiles que se articula con el imaginario social dominante (Baeza 2003, 2007) del orden público visto preliminarmente. Como se puede evidenciar, en este punto se articulan las representaciones y los imaginarios sociales. Sin embargo, en este caso, los imaginarios sociales profundizan los análisis y se nutren de las representaciones para dar cuenta de fenómenos más complejos, como la criminalización de las demandas estudiantiles en 2011.

\subsection{La mediatización de la asociación droga-delito en el diario La Tercera}

En este apartado se aborda la relación droga-delito en un texto periodístico publicado en el diario La Tercera.

\section{Identifican 426 barrios críticos afectados por el narcotráfico}

Autor: Felipe Díaz y Víctor Rivera

Fiscalía elaboró el catastro de las zonas rojas del tráfico de estupefacientes e identificó los principales riesgos de este delito

En Chile existen 426 barrios críticos afectados por el tráfico de drogas, concentrados en 16 comunas de la Región Metropolitana y en otras nueve capitales regionales. En todos estos lugares existen reiteradas condenadas asociadas a este delito entre 2006 y 2016.

Así lo revela el documento titulado "Observatorio del Narcotráfico en Chile 2016", que es una radiografía a este fenómeno delictual. El informe agrupó diversos datos, que incluyen los kilos y tipos de droga incautados, así como las tendencias que configuran el ilícito.

Uno de los puntos esenciales es que las zonas donde se trafican estupefacientes se mantienen en el tiempo, pese a las detenciones y condenas a las que son sometidos los narcotraficantes. El director de la Unidad Especializada en Tráfico Ilícito de Estupefacientes y Sustancias Sicotrópicas de la Fiscalía Nacional, Luis Toledo, dijo que "el objetivo (de la georreferenciación) es entregar una herramienta de trabajo para políticas de prevención y también de persecución penal en materia de tráfico en barrios críticos de nuestro país".

Respecto de las políticas del Estado para enfrentar estos ilícitos, indicó que "no han sido suficientes". Por su parte, el ministro del Interior, Mario Fernández, señaló que "aquí tenemos un muy buen instrumento para mejorar nuestro trabajo frente a este tipo de delitos que tienen, según las cifras que se

${ }^{9}$ Entenderemos por criminalización un sistema organizado de producción de significación que categoriza a un "otro" deslegitimado severamente en su condición socioidentitaria. Por ejemplo, a partir de la noción de estigma propuesta por Goffman y Guinsberg (1970). 
han expuesto, un incremento en Chile".

El documento indica que en 2016 se han incautado 10.613 kilos de marihuana, 5.846 kilos de pasta base y 4.171 kilos de cocaína. Asimismo, revela un dato que es el que más afecta a los narcotraficantes: la cantidad de dinero incautado. Este año la cifra alcanza los $\$ 383$ millones, cifra menor a la registrada en 2015, cuando la policía requisó \$ 1.732 millones a estos delincuentes.

Tendencias

El Observatorio del Narcotráfico también dio cuenta de que Chile se encuentra cerca de tres de los principales países productores de cocaína en el mundo: Perú, Bolivia y Colombia.

Eso ha traído consigo una serie de fenómenos: por ejemplo, la presencia de lanchas rápidas que llegan a playas chilenas con droga desde países del norte, o que en un sector de Alto Hospicio se abastecen traficantes que luego venden droga en el resto del país.

La Fiscalía Nacional también ha detectado que droga proveniente de Colombia viene con determinados sellos. Ante esto, las autoridades chilenas se están comunicando con sus pares colombianos para tener el catastro de estas marcas y así establecer cuál es el cartel que está operando a través de Chile.

Otra tendencia que se detectó es el aumento de la llegada de contenedores que salen de puertos chilenos con destino a África o Australia y que llevan narcóticos escondidos en su interior. En el caso del primer continente, que sirve como paso para llegar a Europa, el informe de la ONU identificó a Chile como la cuarta nación de la cual llegan contenedores con droga oculta, con un 9\% de las menciones. La mayoría de estos embarques salen desde Arica (La Tercera, 14/12/2016).

Como se puede evidenciar, esta noticia se refiere a la localización de zonas específicas donde se desarrolla el tráfico de drogas a raíz de un informe titulado "Observatorio del Narcotráfico en Chile 2016". El procedimiento que utiliza el periodista consiste en reportar la información recabada de dicho estudio a través del discurso referido (estilo directo e indirecto). La metodología del Análisis Sociológico del Discurso (ASD) permite realizar un análisis en distintos niveles que se van articulando con el objetivo de ofrecer una interpretación sociológica de la realidad. De esta manera, se puede apreciar en el nivel textual el contenido de la noticia que aborda los detalles del informe "Observatorio del Narcotráfico en Chile 2016", que pone de relieve los lugares donde se realiza la compra de drogas, las causas que originan el narcotráfico en Chile y la cuantificación en dinero de la droga decomisada por la policía. En un nivel contextual, se pone en relación los elementos textuales y contextuales, en los que se resalta la asociación entre narcotráfico e inmigración, como se puede apreciar en la búsqueda de información por parte de las autoridades chilenas sobre los carteles colombianos que funcionan en el país. Además, se establece una vinculación entre los estudios que reportan el aumento del 
consumo de drogas en los chilenos ${ }^{10} \mathrm{y}$ este informe que detalla las zonas donde se realiza el tráfico de drogas.

En el nivel interpretativo, se puede hacer referencia a la estigmatización de los lugares donde se comercializan las drogas (16 comunas de Santiago y algunas capitales regionales) a través de la expresión "zonas rojas del tráfico de estupefacientes". En efecto, esta expresión evidencia un "estigma territorial", en el sentido de Goffman y Guinsberg (1970), lo que conlleva prejuicios sociales, raciales y tratos discriminatorios. El estigma social de los territorios marginados se ve reforzado por el tratamiento mediático (crónicas rojas, estadísticas policiales) que destaca su "desventaja" en comparación con otros territorios.

En relación a lo anterior, Wacquant (2000) propone la noción de "penalización del mercado laboral", que corresponde a un mecanismo de defensa de los habitantes de los territorios fuertemente estigmatizados que consiste en disimular o esconder su lugar de residencia. Este lugar, etiquetado "socialmente" (Becker, 2009) como peligroso, corresponde, en la lógica de Wacquant, al resultado del deterioro urbano, la exclusión económica, el abandono del gobierno local y el narcotráfico que controla aquellos territorios.

Un análisis en términos de representaciones releva las imágenes existentes sobre los barrios estigmatizados por el consumo y venta de drogas, así como de los consumidores de este producto. De este modo, los "barrios críticos afectados por el tráfico de drogas" activan en los lectores imágenes preconcebidas ligadas, como se mencionó, al deterioro urbano, la prostitución, el abandono y la exclusión social. Por su parte, las representaciones sobre los consumidores de drogas se encuentran asociadas al delito, como se señaló en el texto: “[...] En todos estos lugares existen reiteradas condenas asociadas a este delito [tráfico de drogas] entre 2006 y 2016 [...]". Agreguemos a esto, la existencia de mitificaciones y estereotipos en torno al uso y abuso de drogas (Velásquez 2004; Touzé 2010; Moral, Rodríguez y Ovejero 2010), que conciben al adicto como portador de una enfermedad contagiosa, al margen de toda capacidad de juicio y autocontrol. Así ocurre también con la sustancia, la que es concebida como una entidad con vida propia e independiente de la voluntad de los consumidores.

Un análisis en la lógica de los imaginarios sociales da cuenta de la tensión entre un imaginario social dominante (Baeza 2003, 2007), que concibe el problema de la droga como el gran enemigo interno que puede socavar la seguridad nacional y enfermar el cuerpo social, y el imaginario dominado, que corresponde al discurso de la droga a partir de las experiencias de sus consumidores. En relación el imaginario social dominante

${ }^{10}$ Varios estudios constatan el aumento del consumo de drogas en Chile. Véase http://www. ipsuss.cl/ipsuss/analisis-y-estudios/drogas/estudio-del-senda-revela-aumento-de-215-en-consumode-marihuana-en-seis/2018-01-02/190606.html

EMPIRIA. Revista de Metodología de Ciencias Sociales. N. 41 septiembre-diciembre, 2018, pp. 79-102.

ISSN: 1139-5737, DOI/empiria.41.2018.22605 
(2003), este se nutre de las representaciones sobre las "zonas rojas" del narcotráfico con el fin de proponer una concepción del mundo "libre de drogas" y "abstinente" (Lobos 2012), que corresponde a lo que Ibáñez (1991) denomina el "discurso sobre la droga", es decir, un discurso generado por los medios de comunicación y la institucionalidad médica, jurídica, política y policial, que contiene definiciones sobre la droga y acciones estratégicas de control. En lo que concierne al imaginario social dominado (Baeza 2003, 2007), este se nutre de las vivencias de los consumidores, lo que corresponde para Ibáñez (1991) al "discurso de la droga", es decir el discurso revelado por los propios consumidores que contiene un conjunto de deseos, experiencias, sensaciones y opiniones contrarias al discurso hegemónico dominante.

\subsection{La mediatización del conflicto-chileno mapuche en EI Mercurio y en La Tercera}

En este apartado, se analizarán dos noticias de los diarios El Mercurio y La Tercera que abordan el conflicto chileno-mapuche.

Disminuyen denuncias en la zona del conflicto mapuche y ataques se centran en iglesias

Un $62 \%$ de las denuncias corresponde a ataques incendiarios, que este año han destruido 14 templos en las regiones del Biobío y La Araucanía.

\section{N. Gutiérrez y S. Henríquez}

Bajan las denuncias, pero la violencia se intensifica. Esa es la lectura que hacen desde la Multigremial de La Araucanía de los resultados semestrales que arrojó el Barómetro de conflictos con connotación indígena, en el que la Novena Región registra 75 hechos violentos entre enero y junio de este año.

Aunque la baja es apreciable en relación al mismo período de 2015 -cuando las denuncias llegaron a 152-, según la entidad gremial dicha disminución ha ido de la mano de una mayor violencia y daños en los delitos ocurridos.

"Hoy día la intensidad y la gravedad de estos hechos han ido en aumento, y estos se han ido tornando peligrosísimos. A eso sumémosle que nuevos actores están siendo víctimas, como las comunidades religiosas", expresó Gastón Caminondo, vicepresidente de la Multigremial, en referencia a los 14 atentados incendiarios que en el lapso medido han sufrido iglesias y capillas rurales en La Araucanía y Biobío.

Esta última región y la de Los Ríos presentan casi la misma cantidad de denuncias en relación al primer semestre de 2015. En ambas, también, el blanco suele ser el mismo: faenas y camiones forestales, que totalizaron 33 atentados incendiarios. En este ítem sobresale el ataque a una caravana de 12 camiones forestales -de los cuales seis fueron quemados- el 2 de marzo pasado a plena luz del día, en una carretera resguardada por Carabineros en Tirúa.

En total, en las tres regiones hubo 75 incendios denunciados en el período 
-un $62,5 \%$ del total-, con 22 camiones y 43 maquinarias, principalmente forestal y vial, quemadas entre enero y junio.

\section{Inutilidad de denuncias}

Sin referirse directamente a los números, el intendente de La Araucanía, Andrés Jouannet, dijo que "lo que nos corresponde es que se respete el Estado de Derecho. Y estas situaciones que ustedes observan nosotros las podemos manejar desde el punto de vista de la seguridad, desde el punto de vista del orden (...) Ha sido un trabajo arduo".

Para el presidente de la Sociedad de Fomento Agrícola de Temuco (Sofo), Marcelo Zirotti, las menores denuncias no obedecerían necesariamente a una menor ocurrencia de delitos, sino al hecho de que muchas víctimas se inhiben de presentarlas, principalmente en el caso de los pequeños agricultores.

"Hay gente que se abstiene de denunciar porque sabe que no tiene un fin, que va a ser solamente una pérdida de tiempo ir a fiscalía y contratar abogados. Y el perjudicado es casi siempre el pequeño productor que no cuenta con medios. Se queda sin fuente de trabajo, sin capital, y encima tiene que hacer un gasto", argumentó.

\section{Templos quemados}

La gran diferencia de esta entrega del Barómetro con las anteriores se relaciona con un nuevo fenómeno: los incendios de capillas y templos rurales en la zona.

Este año han sido atacados 14 templos, ocho católicos y seis evangélicos. El fenómeno se desató en abril de este año, un mes después de que la Diócesis de Villarrica ordenara el desalojo del Seminario Mayor San Fidel, que estuvo casi dos años tomado por mapuches.

Desde entonces, la comuna más golpeada por este tipo de ataques ha sido Padre Las Casas, con ocho atentados. En casi todos los casos se hallaron panfletos, y a través de un comunicado un grupo denominado Wichan Auka Mapu se adjudicó la totalidad de los incendios, además de otros ocurridos en años anteriores.

La Comisión Asesora Presidencial para La Araucanía ha sido la instancia que el Gobierno estableció para abordar el conflicto mapuche. La semana pasada cumplió su segunda sesión y, pese a las críticas que han surgido, el vicepresidente de la Multigremial la consideró como un esfuerzo válido.

"A estas alturas, una mesa más o una mesa menos, igual hay que poner las fichas y la energía para que esto llegue a buen término, para que esto se encamine a una probable solución al conflicto. Las regiones afectadas ya no pueden seguir esperando" subrayó (El Mercurio, 27-07-2016).

En esta noticia se reportan las opiniones de diferentes locutores (Multigremial, gobierno y la Sofo) a propósito de los resultados que arrojó el "Barómetro de conflictos con connotación indígena”. El procedimiento utilizado por los periodistas consiste en reportar la información recabada de este estudio y exponer las opiniones a través de la citación de los principales actores del conflicto, acorde las restricciones propias del género discursivo de la noticia. 
La metodología del Análisis del Discurso permite centrarse en ciertos elementos presentes en la "materialidad discursiva" (Pêcheux, 1969), tales como palabras, sintagmas nominales, verbos y construcciones sintácticas. De esta manera, se puede evidenciar en el texto el sintagma "zona del conflicto mapuche", que corresponde a una variante del sintagma nominal "conflicto mapuche". Este sintagma ha sido objeto de varios estudios ${ }^{11}$ que revelan lo excluyente y sesgado de esta expresión, que oculta a los otros actores del conflicto (los agricultores, las empresas forestales y el Estado). Junto a ello, categoriza bajo un término (en este caso un sintagma) una multiplicidad de acontecimientos políticos, sociales, religiosos y étnicos diferentes, cuyo rasgo fundamental es la violencia irracional cometida por los mapuches. Nótese que en el texto el sintagma "conflicto mapuche" aparece sin comillas, como una expresión naturalizada, lo que invisibiliza los debates y cuestionamientos de los sectores progresistas sobre la utilización de esta expresión que responsabiliza a los mapuches del conflicto actual.

Otro aspecto que llama la atención en el texto corresponde al estatus de los locutores convocados para dar su opinión sobre los acontecimientos. En efecto, los periodistas utilizan fuentes oficiales y que poseen prestigio en la región, tales como la Sociedad de Fomento Agrícola de Temuco (Sofo), la Multigremial de La Araucanía, compuesta por la Asociación de la Industria del Salmón de Chile, la Corporación Chilena de la Madera, la Asociación Gremial Dueños de Camiones de Malleco y Cautín, entre otras, y el intendente de la región de la Araucanía, Andrés Jouannet. Como se observa, no existen fuentes que representan la opinión de las comunidades mapuches. Este procedimiento de invisibilizar la opinión de las comunidades mapuches en este tipo de acontecimientos ligados a la violencia corresponde a algo habitual, tal como lo han señalado Merino y Pilleux (2003) y Van Dijk (2007), en lo que respecta al control de las fuentes por parte de los periodistas. Esto permite construir una visión particular del llamado conflicto chileno-mapuche, en la que se resalta la violencia de parte de los mapuches, lo que nos remite a una manera de representar la identidad de los participantes de la noticia.

Un análisis en el nivel de las representaciones sociales pone acento en las construcciones identitarias de los participantes de la noticia. Por una parte, se puede hacer referencia a la construcción de víctimas del conflicto, que corresponde a los "pequeños productores", "camiones forestales", "iglesias y capillas rurales" y "comunidades religiosas", que se realiza a través de construcciones pasivas, tales como "fueron quemados [los camiones]", "han sido atacados" [los templos], así como mediante el uso de estadísticas y el detalle de los bienes de capitales perdidos. Por otra parte, en el texto se puede evidenciar la representación identitaria de los causantes de estos acontecimientos, que corresponde a los mapuches. Si bien el "objeto del discurso", en el sentido de Grize (1996), se centra en las opiniones y reacciones de los actores económicos de la región, se

11 Véase los trabajos de Bengoa (2000), Pinto (2003) y Segovia $(2015,2016)$ sobre este tema. 
hace referencia explícita a los mapuches solo dos veces: cuando se menciona la ocupación por dos años del Seminario San Fidel y la referencia al "grupo denominado Wichan Auka Mapu", responsable de los ataques a las iglesias rurales. En ambas menciones se vehiculan representaciones de los mapuches caracterizadas por sus rasgos violentos e irracionales, lo que participa fuertemente en la estigmatización de este grupo social. Señalemos la referencia implícita a los mapuches en el título del informe semestral de evaluación social y política llamado "Barómetro de conflictos con connotación indígena". Como se puede apreciar, el título de este informe, específicamente el complemento del nombre "con connotación indígena", conlleva un implícito que apunta a la responsabilidad de los mapuches en los actos de violencias señalados en este documento. De esta forma, se podría señalar que cada referencia explícita que hace este informe sobre las víctimas del conflicto tiene su contraparte implícita acerca de los causantes de tal violencia.

Un análisis a nivel de imaginarios sociales resalta la tensión entre un imaginario dominante (Baeza 2003, 2007), que propone el respeto irrestricto del Estado de derecho y un imaginario social dominado, que corresponde a las demandas de las organizaciones mapuches. En relación al imaginario social dominante (Baeza 2003), este se nutre de las representaciones existentes sobre los mapuches y de los otros participantes del conflicto (agricultores y empresarios) revisados anteriormente, lo que refuerza la criminalización de las demandas mapuches y la utilización de la fuerza policial. Por su parte, el imaginario social dominado (Baeza 2003, 2007), se nutre del discurso que surge entre las organizaciones mapuches y las organizaciones internacionales, tales como la ONU y la OIT, que condenan el accionar represivo y discriminatorio del Estado chileno. Este imaginario se encuentra invisibilizado en los diarios El Mercurio y La Tercera que proponen una determinada construcción social de la realidad, en el sentido de Berger y Luckmann (1976).

Revisemos a continuación otro extracto de noticia:

\footnotetext{
Gobierno descarta retirar querella por terrorismo a mapuches en huelga de hambre (titular).

El gobierno de Chile descartó este sábado retirar la querella por infracción a la ley antiterrorista contra cuatro comuneros mapuches en prisión preventiva, imputados por el incendio de una iglesia, que supuestamente llevan 109 días en huelga de hambre (lead o encabezado) (La Tercera, el 23-11-2017).
}

En el titular de la noticia podemos encontrar una asociación entre mapuche, terrorismo y huelga de hambre. Estos elementos se encuentran frecuentemente asociados cuando se trata de destacar la posición de los grupos de poder en la Araucanía (agricultores, empresarios forestales), que ejercen presión sobre el gobierno de Chile. Respecto a este punto, existe bastante bibliografía que da cuenta de la formación de grupos que ejercen poder en la IX región y que se 
vieron favorecidos por los gobiernos de turno (Pinto, 2015). En el caso de los agricultores y hacendados, estos recibieron enormes terrenos o los compraron a una módica suma, luego de la ocupación militar del Estado de Chile sobre los territorios mapuches a fines del siglo XIX. Posteriormente, ellos continuaron ejerciendo presión durante todo el siglo XX sobre los escasos territorios indígenas que quedaron luego de las reducciones de 1920 (Pinto, 2015). En el caso de las empresas forestales, la dictadura militar de Pinochet otorgó grandes terrenos a las empresas para la plantación del pino y el eucalipto, subsidiando más del 60 $\%$ de sus costos (Bengoa, 2000). Esto permitió la conformación de un grupo de empresarios poderosos gracias a sus vínculos con los parlamentarios de derecha y con los agricultores de la zona.

Ambos grupos, a partir de 1990, ejercieron presión contra el gobierno para que se aplicara la ley antiterrorista a los casos vinculados con violencia y demandas de territorios (Pinto, 2015). La aplicación de esta ley, que data de la dictadura de Pinochet (1973-1989), ha sido fuertemente contestada por diferentes organismos internacionales (la OIT y la ONU), que condenan el uso de este instrumento legal para tratar los conflictos sociales. Lo cierto es que esta vinculación entre demandas territoriales y terrorismo deja entrever una forma de categorizar el accionar de los mapuches como algo fuera de la legalidad vigente y que atenta contra el Estado de Derecho. Al mismo tiempo, se estigmatiza a los mapuches como supuestos terroristas, a través de una designación calificante de carácter negativo que arrastra los diferentes significados que ha tenido la palabra terrorista a lo largo del tiempo (terrorismo político y terrorismo religioso). En este punto, nos conectamos con las representaciones sociales que circulan en Chile sobre los grupos que ejercen el terrorismo, lo que nos remite a los acontecimientos vividos durante la dictadura de Pinochet (1973-1989), en la que la palabra terrorismo era utilizada para designar a los grupos de oposición que se identificaban con el marxismo. Si tomamos el postulado de Bajtín (1986), que señala que las palabras "son portadoras de memoria", podríamos decir que la utilización de la palabra terrorismo busca asociar las demandas mapuches con acciones ilegales y contrarias a los intereses del Estado. De este modo, se deslegitima en los diarios El Mercurio y La Tercera las demandas de las organizaciones mapuches.

Un análisis en el nivel de las representaciones se centra en las construcciones simbólicas en torno a la designación calificante "terrorista" y en su capacidad de contribuir al sentido de los enunciados. Desde esta perspectiva, las representaciones que circulan en el espacio público sobre los mapuches (violento, indómito, agresivo, fuera de la ley) contribuyen a dar inteligibilidad a la relación entre las demandas mapuches y el terrorismo. Un análisis en el nivel de los imaginarios sociales enfatiza no sólo las construcciones simbólicas de la palabra "terrorista", sino también el imaginario social dominante, en el sentido de Baeza (2003, 2007), que nutre estas representaciones y que corresponde al respeto irrestricto del Estado de derecho y del orden público. De esta manera, a partir de este imaginario se articula una política represiva desde el Estado y la criminalización de las demandas mapuches, lo que refuerza la idea del mapuche 
terrorista concebido como una amenaza para el Estado chileno. Cabe señalar que este imaginario se encuentra estrechamente ligado a dos conceptos de la Historia de Chile que se remontan al siglo XIX: una concepción del Estado chileno como único e indivisible (Bengoa, 2000; Marimán, 2006) y una ideología de la negación del otro (Pinto, 2003) que consiste en afirmar la superioridad del mundo Occidental sobre el indígena.

A este respecto, resultan útiles las reflexiones de Baeza (2007), quien sostiene que en el caso del mapuche existe una correspondencia entre una ideología de la negación del indígena y los imaginarios sociales dominantes. Esto permitió la naturalización de ciertas características subjetivas del mapuche (indio violento, flojo, borracho, terrorista), que ahora forman parte de la doxa, en el sentido de Aristóteles, y que se pueden observar en ciertas expresiones idiomáticas del Español de Chile, tales como "se le salió el indio" y "se le paró la pluma", para referirse a reacciones de enojo y violencia.

\section{CONSIDERACIONES FINALES}

En este trabajo se ha reflexionado sobre las nociones de representaciones e imaginarios sociales a través del análisis de cinco noticias de los diarios El Mercurio y La Tercera, pertenecientes a tres ámbitos distintos, con el fin de identificar los aportes de estas nociones en la construcción de una realidad social movilizada por la prensa escrita chilena.

En los análisis de los textos, realizados con diferentes metodologías (Análisis de Contenido, Análisis Sociológico del Discurso y Análisis del Discurso), es posible evidenciar la importancia de las nociones de representaciones e imaginarios para dar cuenta de los elementos de naturaleza simbólica que participan en la construcción de sentido del texto. Específicamente, se reflexionó sobre la complementariedad de ambas nociones al momento de analizar los textos, así como también de sus diferencias, dado que la representación está destinada a la percepción de imágenes culturales, en el sentido de Jodelet (1984), mientras que los imaginarios, en el sentido de Castoriadis (1989), buscan el origen, el elemento fundante, que inspira la creación de estas imágenes culturales.

En el ámbito del tratamiento mediático del movimiento estudiantil de 2011, las representaciones que circulaban en la prensa escrita nos remitían a imágenes culturalmente compartidas (joven rebelde y anti sistémico), mientras que los imaginarios sociales aludían a significaciones más profundas como la tensión existente entre imaginarios sociales dominantes (legitimidad del orden neoliberal y resguardo del orden público) y dominados (la legitimación de la Educación como un derecho). En el ámbito de la cobertura mediática de la asociación droga-delito, las representaciones nos remitían a imágenes culturales ligadas a la pobreza, la exclusión social y la baja escolaridad, en tanto que los imaginarios sociales aludían a las tensiones entre un imaginario social dominante (la droga como enemigo interno) y otro dominado (discurso de la droga a partir de sus consumidores). En lo que respecta al tratamiento mediático del conflicto chileno- 
mapuche, las representaciones nos remitían a imágenes culturalmente compartidas (mapuche violento, flojo y terrorista), mientras que los imaginarios sociales aludían a la tensión entre un imaginario social dominante (respeto irrestricto del Estado de Derecho y resguardo del orden público) y un imaginario dominado (derecho a la autodeterminación mapuche como pueblo autónomo).

Como se observa, las nociones de representaciones e imaginarios pueden articularse de manera complementaria (debido a la naturaleza simbólica de ambas nociones), las cuales pueden ser visibilizadas en la prensa escrita, permitiendo profundizar los análisis y proponer una interpretación basada en la articulación de elementos discursivos, sociales y políticos. Esto último puede darnos luces sobre la forma en que la prensa escrita construye realidad social, en el sentido de Berger y Luckmann (1976), lo que funciona como matriz explicativa para dar sentido a la complejidad del mundo social.

\section{REFERENCIAS BIBLIOGRÁFICAS}

ALIAGA, F., BASULTO, Ó y APOLO, D (2015): "Reacciones sociales e invisibilidad mediática frente al imaginario del joven problema", En Diálogos sobre juventud en Iberoamérica, Santiago de Compostela, Universidad de Santiago de Compostela, pp. $15-32$.

ARNOLD. M. (2003): "Fundamentos del Constructivismo Sociopoiético", Cinta de Moebio. Revista Electrónica de Epistemología de las Ciencias Sociales, 18, pp. $162-173$.

ARRUE, M. (2012): "El movimiento estudiantil en Chile (2011-2012): Una lucha contra la discriminación", Amérique Latine Histoire et Mémoire. Les Cahiers ALHIM, 24, disponible en http://journals.openedition.org/alhim/4388 [consultado el 31 de mayo de 2018]

BAEZA, M. (2003): Imaginarios sociales, Apuntes para la discusión teórica y metodológica, Concepción, Editorial Universidad de Concepción.

(2007): "Imaginarios sociales dominantes de un otro inferiorizado: el caso del Indígena en Chile", XXVI Congreso de la Asociación Latinoamericana de Sociología, disponible en http://cdsa.aacademica.org/000066/950.pdf [consultado el 31 de mayo de 2018]

(2008): Mundo Real, Mundo Imaginario Social. Teoría y práctica de sociología profunda, Santiago, RIL Editores.

BAJTIN, M. (1986): Problemas de la poética de Dostoïevski, México. D.F., FCE.

BARDIN, L. (1996): Análisis de Contenido, Madrid, Akal.

BARRERA, I. (2017): Percepción de los estudiantes de primer año de enseñanza media con Trastorno de Déficit Atencional con y sin Hiperactividad (TDAH/TDA), acerca de los diferentes factores que influyen en su proceso de aprendizaje (tesis de maestría), Universidad Católica de la Santísima Concepción, Chile.

BECKER, H. (2009): Outsiders hacia una sociología de la desviación, Buenos Aires, Siglo XXI.

BENGOA, J. (2000): Historia del pueblo mapuche (siglo XIX y XX), Santiago, LOM. 
BERGER, P y LUCKMANN, T. (1976): La construcción social de la realidad, Buenos Aires, Amorrortu.

CASTORIADIS, C. (1989): La Institución Imaginaria de la Sociedad, Buenos Aires, Tusquets Editores.

COLOMA, R. y AGÜERO, C. (2014): "Fragmentos de un Imaginario Judicial de la Sana Crítica", Ius et Praxis, 20(2), pp. 375-414.

DITTUS, R., BASULTO, Ó. y RIFFO, I. (2017): “La investigación en Chile sobre imaginarios y representaciones sociales", Cinta de Moebio, Revista Electrónica de Epistemología de las Ciencias Sociales, 58, pp. 103-115.

DONOT, M. y PORDEUS, M. (2012) : Discours politiques en Amérique latine. Représentations et imaginaires, Paris, L'Harmattan.

FIGUEROA, B., AILLON, M., NEIRA, A. y UBILLA, L. (2017): "Representaciones sociales del contexto comunitario, escenarios para generar prácticas de escritura", Educação \& Sociedade, vol. 38(45), pp. 893-910.

GADAMER, H. G. (2000): Verdad y Método I. Fundamentos de una Hermenéutica filosófica, Salamanca, Sígueme.

GOFFMAN, E. y GUINSBERG, L. (1970): Estigma: la identidad deteriorada, Buenos Aires, Amorrortu.

GRIZE J.-B. (1996): Logique naturelle et communications, Paris, PUF.

HUSSERL. H. (1985): Ideas relativas a una fenomenología pura y una filosofía fenomenológica, Madrid, Fondo de Cultura Económica.

IBAÑEZ, J. (1991): El discurso de la droga y los discursos sobre la droga, Ponencia presentada en el Primer encuentro Nacional sobre Sociología y Drogodependencias. Universidad Complutense, España.

JODELET, D. (1984): "La representación social: fenómeno, conceptos y teoría", En MOSCOVICI. (Comp.), Psicología Social II, Barcelona, Paidós, pp. 478-494.

LOBOS, M. (2012): Políticas públicas para el tratamiento y rehabilitación de personas con consumo problemático de drogas. Análisis crítico desde la experiencia práctica en el Centro Comunitario de Salud Mental (COSAM) de Conchalí (tesis de pregrado), Universidad de Chile, Chile.

MARIMAN, P. (2006): "Los mapuches antes de la conquista militar chileno argentina", En P. MARIMÁN, S. CANIUQUEO, J. MILLALÉN y R. LEVIL. (Eds.), ; ...Escucha winka...! Cuatro ensayos de Historia Nacional Mapuche y un epílogo sobre el futuro, Santiago, LOM, pp. 53-126.

MAINGUENEAU, D. (2014): Discours et analyse du discours, Paris, Armand Colin.

MARTYNIUK. C. (1994): Positivismo, hermenéutica y teoría de los sistemas sociales. Tres posiciones epistemológicas en las ciencias sociales, Buenos Aires, Ed. Biblos.

MERINO, M. E. y PILLEUX, M. (2003): "El uso de estrategias semánticas globales y locales en el discurso de los chilenos no mapuches de la ciudad de Temuco", Estudios Filológicos, 38, pp. 111-119.

MOIRAND, S. (2007): Les discours de la presse quotidienne. Observer, analyser, comprendre, Paris, PUF.

MORAL, M., RODRÍGUEZ, F. y OVEJERO, A. (2010): “Correlatos psicosociales del consumo de sustancias psicoactivas en adolescentes españoles", Salud Pública de México, 52(5), pp. 406-415.

MOSCOVICI, S. (1961): El psicoanálisis, su imagen y su público, Buenos Aires, Huemul.

PÊCHEUX, M. (1969): L'analyse automatique du discours, Paris, Dunod. 
PINTO, J. (2003): La formación del Estado y la nación y el pueblo mapuche. De la inclusión a la exclusión. Santiago, Dirección de Bibliotecas, Archivos y Museos (Dibam).

PINTO, J. (ED.). (2015): Conflictos étnicos, sociales y Económico. Araucanía 19002014, Santiago, Pehuén.

PINTOS, J. (1995): Los imaginarios sociales. La nueva construcción de la realidad social, Salamanca, Fe y Secularidad.

RUIZ, J. (2009): “Análisis sociológico del discurso: métodos y lógicas”, Forum: Qualitative social research, 10(2), pp. 1-32.

SEGOVIA, P. (2015): “Nommer le 'conflit mapuche' dans la presse chilienne", En A, RICHARD., F, HAILON Y N, GUELLIL. (Dirs.), Le discours politique identitaire dans les média, Paris, L'Harmattan, pp. 139-165.

(2016): "La construction discursive de l'événement conflit mapuche dans la presse écrite chilienne", Synergies Chili, 12, pp. 73-87.

SEVESO, E. (2009): "Imágenes de la diferencia. Construcción subjetiva, otredad y medios de comunicación”, Fundamentos en Humanidades, Año X(19), pp. 9-23.

SCHÜTZ. A. (1993): La construcción significativa del mundo social. Introducción a la sociología comprensiva, Barcelona, Paidós.

TOUZÉ, G. (2010): Prevención del consumo problemático de drogas. Un enfoque educativo, Buenos Aires, Troquel.

VAN DIJK, T. (2007): Racismo y Discurso en América Latina, Barcelona, Gedisa.

VELÁSQUEZ, V. (2004): Estudio sobre consumo de drogas en jóvenes estudiantes de pregrado de la Universidad de la Frontera de Temuco (tesis de pregrado), Universidad de Chile.

VERÓN, E. (1993): La semiosis social. Fragmentos de una teoría de la discursividad, Barcelona, Gedisa.

WACQUANT, L. (2000): Las cárceles de la miseria, Buenos Aires, Ed. Manantial.

ZAMBRANO, P. (2017): De biopoder y discursos en la construcción imaginario social: En Población condenada a penas sustitutivas derivada a tratamiento de drogas y/o alcohol en la Provincia de Concepción (tesis de pregrado), Universidad de Concepción, Concepción, Chile. 